Original Research

\title{
Design optimization of multi energy systems for domestic hot water uses on the building sector
}

Vasileios Kilis 1, Nikolaos Ploskas 2, Giorgos Panaras 1,*

1. Department of Mechanical Engineering, University of Western Macedonia, Bacola \& Sialvera, 50132, Kozani, Greece;

E-Mail:mpl00012@uowm.gr

2. Department of Electrical and Computer Engineering, University of Western Macedonia, Karamanli \& Ligeris, 50131, Kozani, Greece; E-Mail:nploskas@uowm.gr

* Correspondence: Giorgos Panaras; E-Mail: gpanaras@uowm.gr

Received: 30 Sep 2021

Accepted: 4 Nov 2021

Published: 17 Dec 2021

Copyright: (c) 2021 by the author(s). This is an Open Access article distributed under the terms of the Creative Commons License Attribution 4.0 International (CC BY 4.0), which permits unrestricted use, distribution, and reproduction in any medium or format, provided the original work is correctly credited.

Publisher's Note: Pivot Science Publication Corp. remains neutral with regard to jurisdictional claims in published maps and institutional affiliations.

\begin{abstract}
The burden that has come upon the environment, combined with the ever-declining fossil fuel reserves, has led to the need of reducing the conventional energy consumption in building sector and to the promotion of systems based on Renewable Energy Sources (RES). This paper deals with the optimization of multi energy systems in order to cover the needs of hot water in domestic use. In particular, integer linear programming models are formulated and the optimal solutions regarding the degree of participation of the multi energy systems are explored; economic, energy, and environmental criteria are assumed. The respective mathematical programming approaches include linear objective functions, multiple objective functions that either do or do not use weights, as well as goal programming-based ones. The modeling and solution of the problems is done with the General Algebraic Modeling System (GAMS).

The case study refers to residential use; both conventional and RES systems are selected for the respective energy demand coverage. The time step of the analysis is 1 hour, in the context of annual operation. According to the results, in the case of the energy criterion, biomass predominates, or heat pumps, when biomass is not included, with an increase in participation of solar thermal collectors when the environmental criterion is introduced. The participation of solar thermal factor is also reinforced in the case of goal programming, because of the relaxation of the initial targets. The analysis demonstrated that the existing integer linear programming
\end{abstract}


methodological tools can be used for investigating problems of multiple energy systems or comparing subsystems.

Keywords: optimization; multi energy systems; energy hub; linear programming; domestic hot water; renewable energy systems

\section{Introduction}

One of the most crucial issues worldwide, especially in the last two decades, is the increase of the energy consumption due to the increase of the world population, but also to the economic development. In the European Union (EU-27), according to published data of 2019, it can be seen that the residential building sector is responsible for $26 \%$ of the total energy consumption [1]. The EU is particularly concerned with limiting the energy consumption of the building sector, as it is demonstrated by the Energy Performance of Buildings Directive (EPBD) [2] and its recasts, mentioning the most recent one [3]. Moreover, the EU has set ambitious goals to reduce the consumption of primary energy, which is based on fossil fuel, and consequently Carbon Dioxide $\left(\mathrm{CO}_{2}\right)$ emissions to the atmosphere. A relevant reference goal of EU anticipated that newly constructed buildings should be in compliance with the specifications of near Zero Energy Building (nZEB); a deadline of 31 st December 2020 was set. Regarding future prospects, the imposed targets for 2030 refer to: (a) an initial reduction of at least $40 \%$ of greenhouse gas emissions, comparing to levels of 1990, (b) an allocation of at least $32 \%$ of energy used to the RES and (c) an improvement of at least $32.5 \%$ in the energy efficiency of the energy systems used [4].

Covering the energy needs for domestic water heating in the building sector is an important aspect for the total energy consumption of a building, as it is demonstrated by relevant published data [5-7]. More particularly, the energy consumption for heating water in Greek households for 2019 , approaches the percentage of $13.3 \%$ of the total building energy consumption, while $56.3 \%$ of this consumption is for heating, $19.2 \%$ is for electricity and electrical appliances, and small percentages of about $6.2 \%$ and $4.9 \%$ are related to cooking and cooling, respectively [8]. In addition to the above, water heating can be demanding on a financial level, while burdening for the environment; apart from the number of residents/users and the type (use) of the building, its cost and impact are strongly related to the energy system (fuel source) that it is used. Thus, the determination of the optimal solution, given the above parameters and criteria $[9,10]$, can be important for the user, as well as on a local and global level. 
In this work, mathematical optimization models, describing the participation rates of energy systems for covering the hot water needs for sanitary use of a household, are formulated. Mathematical optimization modeling is usually implemented in different case studies and its implementation in household energy systems is an innovative aspect [11]. The concept of multi energy systems is introduced, i.e., a group of systems that uses different energy sources [12] but can be used in order to cover the same type of energy demand, forming an energy hub [13]. In literature the establishment and operation of energy hubs is a commonly used aspect, and especially when they are formulated to serve optimization models, whose main objective is the minimizing of energy costs $[14,15]$. The proposed energy hub is presented in Figure 1, anticipating the presence of the following systems: (a) biomass boiler (wd), (b) oil boiler (bl), (c) electric water heater (el), (d) solar thermal water heater (sol), and (e) an air to water heat pump (hp). Such systems can be considered typical for residential Domestic Hot Water (DHW) in Greece [16-19]. The inputs of the present energy hub refer to the hourly energy demands of DHW ( $\left.Q_{\text {dem, }} \mathrm{DHW}\right)$, while by introducing the efficiencies $(n)$ and the participation rates (e) of each aforementioned energy systems, the energy consumptions ( $Q_{\text {cons, }}$ DHw) emerge, which is the output of the energy hub. The case study refers to a house with a total area of $200 \mathrm{~m}^{2}$. Given that, according to the Greek version of the EPBD [20], the area of the building is proportional to the number of residents and to the hot water energy demands, it is indicated that the demonstrated results are not sensitive to the assumed building area. In the proposed analysis, the building has been placed in climatic zones $A$ and $D$, representing the marginal climatic conditions for the Greek setting [21].

The investigation of the model optimal solution concerns a financial, energy, and environmental criterion. The results of the models used are presented on an hourly basis for the whole operation year of the energy systems and they are obtained by the solver CPLEX.

Overall, the innovation of this study is that mathematical programming models are formed to select the optimal energy system taking into consideration the economic, energy and environmental criteria. What stands out is the low time step used for the model solutions, turning the problem into a dynamic like one, so that the comparison between the examined energy systems and the decision making would be more detailed.

In the following sections, the methodology of developing the proper mathematical models is presented. These models deal with the optimization of the participation rate of each energy system, which is used in covering the demands of DHW. At first, the selection of the appropriate energy systems and the definition of their characteristics, such as their efficiencies or their costs, seems to be critical for the 
investigation. Afterwards, the description of the basic parameters follows. Such parameters are used in the calculation of the energy loads and consumption, and the installed power of each energy system. Finally, the formulation of the optimization models is analyzed; results and basic conclusions are presented.

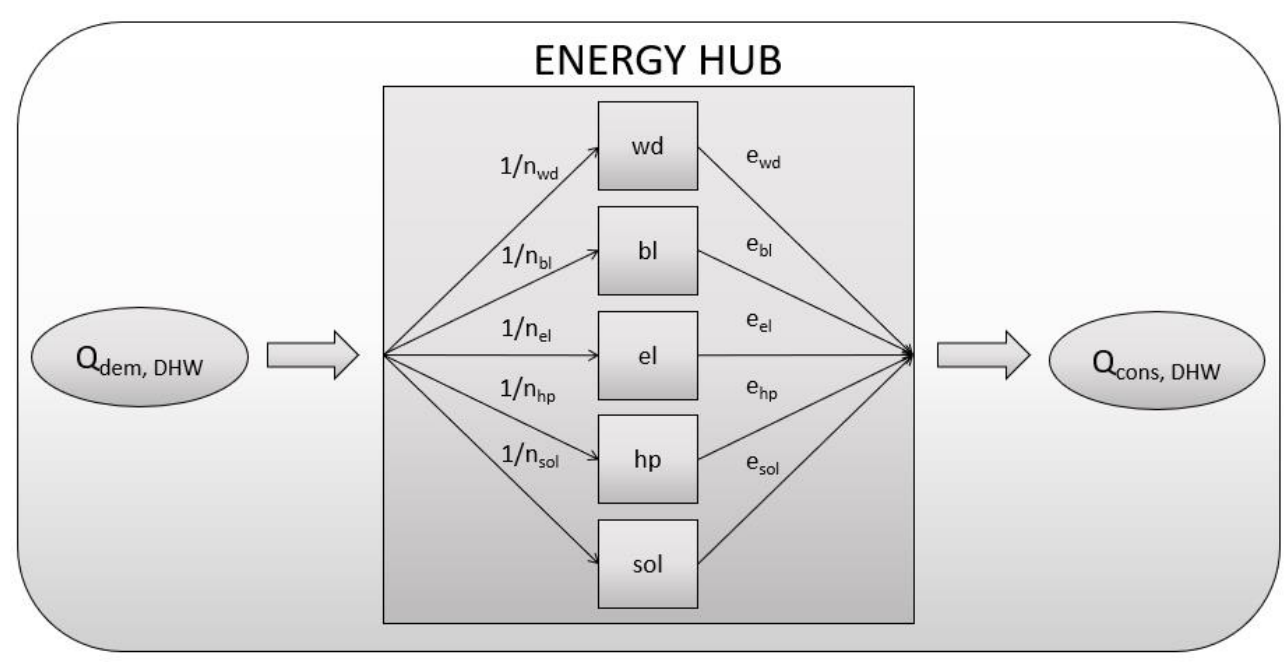

Figure 1 The energy hub of the multi energy system used for DHW uses.

\section{Methods}

\subsection{Basic parameters}

\subsubsection{Characteristics of multi energy systems}

In this paper, the examined energy systems refer to a biomass boiler, an oil boiler, an electric water heater, a solar thermal water heater and an air to water heat pump. The efficiency of the adopted energy systems is in compliance with the Greek version of the EPBD [20]. The values have also included potential network heat losses (Table 1). Especially for the solar thermal system, the respective efficiency is focused on the aspect of thermal losses, as the actual one is calculated on the basis of the Capacity Factor (CF), as it is indicated in Section 2.1.2. For all considered energy systems, the efficiency could be considered as constant; the only exception refers to the heat pump. This occurs due to the dependence of the heat pump efficiency on the air temperature. Thus, it is important to calculate this parameter on an hourly basis according to the relevant climatic data [21]; the following Equation (1) is used [22].

$$
C O P=0.001 \cdot \Delta T^{2}-0.1534 \cdot \Delta T+7.3775
$$

where:

- COP [-]: the heat pump coefficient of performance calculated per hour. 
- $\Delta \mathrm{T}\left[{ }^{\circ} \mathrm{C}\right]$ : the temperature difference between the air temperature and the output temperature of the working mean (water), considered at $50^{\circ} \mathrm{C}[21]$.

An important aspect that should be mentioned refers to the cost, whether this indicates installation or operational (energy and environmental) one, noting that the environmental factor considers the amount of released $\mathrm{CO}_{2}$, which is the dominant greenhouse gas. The unit cost values are based on market research for typical energy systems and on current prices of providers or suppliers. The values that are used for this investigation are presented in Table 1. In some cases, two values are provided, as in the case of oil and electrical energy; this price diversification was preferred in order to explore the impact of possible economic measures aimed at saving energy in the final solution (e.g., social or night tariff).

Table 1 Efficiency, life duration and cost for each energy system $[11,16,17]$.

\begin{tabular}{c|c|c|c|c|c}
\hline Energy Systems & $\begin{array}{c}\text { Efficiency } \\
(\mathbf{\%})\end{array}$ & $\begin{array}{c}\text { Energy Costs } \\
\mathbf{(} \mathbf{\epsilon} / \mathbf{k W h})\end{array}$ & $\begin{array}{c}\text { Installation } \\
\text { Costs } \\
\mathbf{(} \mathbf{\epsilon} / \mathbf{k W})\end{array}$ & $\begin{array}{c}\text { Environmental } \\
\text { Costs } \\
(\boldsymbol{\epsilon} / \mathbf{k W h})\end{array}$ & $\begin{array}{c}\text { Life Duration } \\
\text { (years) }\end{array}$ \\
\hline Oil boiler & 80 & $0.025 / 0.1$ & 100 & 0.04 & 20 \\
Biomass boiler & 90 & 0.04 & 250 & 0 & 15 \\
Electric heater & 95 & $0.05 / 0.15$ & 100 & 0.065 & 15 \\
Heat pump & varying & $0.05 / 0.15$ & 250 & 0.065 & 15 \\
Solar thermal & 95 & 0 & $450\left(€ / \mathrm{m}^{2}\right)$ & 0 & 15 \\
heater & $(\mathrm{CF}=0.4)$ & & & & \\
\hline
\end{tabular}

\subsubsection{Energy parameters}

Initially, the calculation of the DHW energy demand on monthly basis is implemented (Equation (2)). Results are presented in Figure 2 for both the examined climatic zones, indicating that, for the needs of the analysis, these values are properly converted to hourly ones.

$$
Q_{D H W}=V_{W} \cdot N_{d a y, i} \cdot \frac{\rho \cdot c_{p}}{3600} \cdot\left(T_{D H W, i}-T_{w, i}\right)
$$

where:

- Q QHW [kWh]: monthly required energy load to cover the needs of DHW.

- $V_{W}[\mathrm{l} /$ day]: daily volumetric water supply.

- $\quad \mathrm{N}_{\text {day,i }}$ [days]: number of days of each month.

- $\rho\left[\mathrm{kg} / \mathrm{m}^{3}\right]$ : density of water $\left(=1 \mathrm{~kg} / \mathrm{m}^{3}\right)$.

- $\quad c_{p}[\mathrm{~kJ} / \mathrm{kg} \mathrm{K}$ : water heat capacity $(=4.18 \mathrm{~kJ} / \mathrm{kg} \mathrm{K})$.

- $\mathrm{T}_{\mathrm{DHW}, \mathrm{i}}\left[{ }^{\circ} \mathrm{C}\right]$ : required temperature of $\mathrm{DHW}\left(=45^{\circ} \mathrm{C}\right)$.

- $\mathrm{T}_{\mathrm{w}, \mathrm{i}}\left[{ }^{\circ} \mathrm{C}\right]$ : mains water average monthly temperature [21]. 


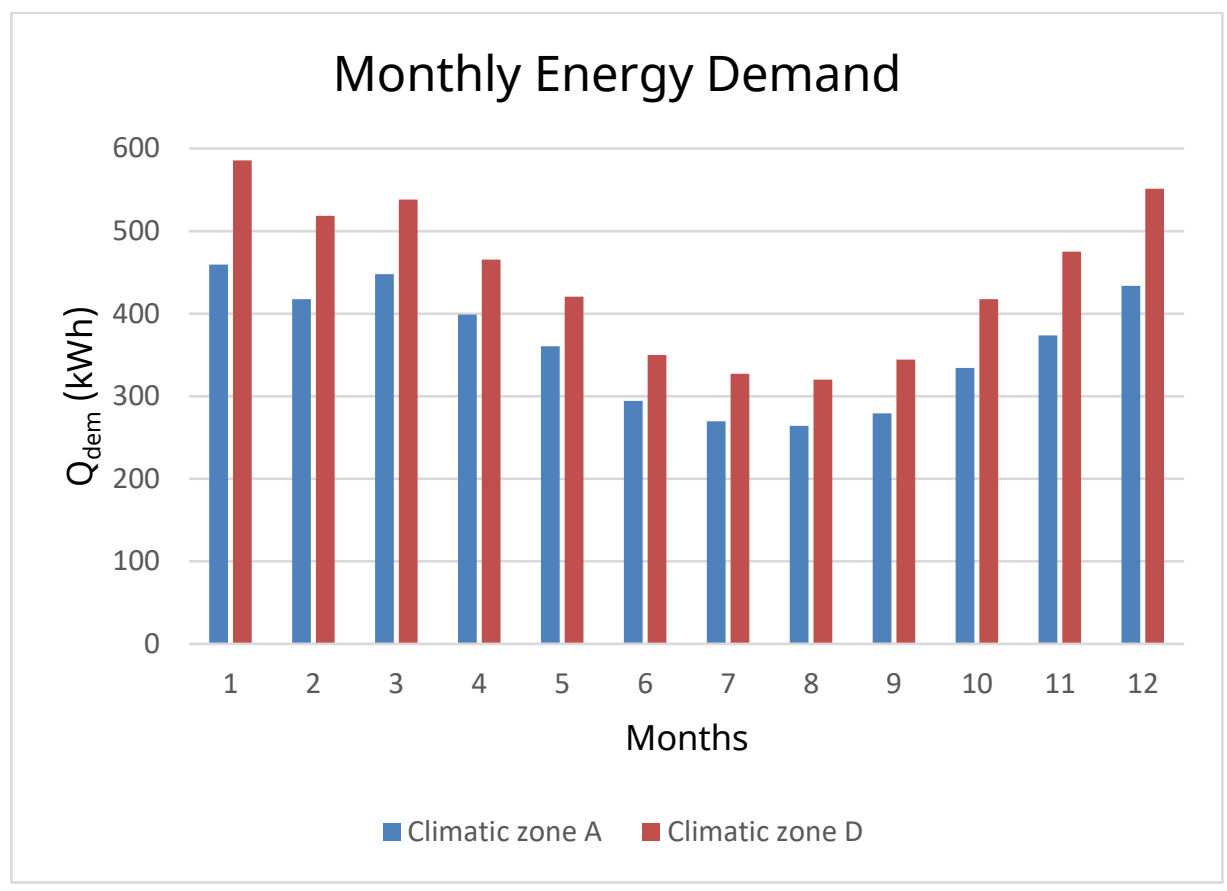

Figure $\mathbf{2}$ The monthly energy requirement for climatic zones A and D.

From the graph presented in Figure 2, it is obvious that the energy demand in climatic zone $D$ is higher than the ones in A for every month, due to the worst climatic conditions prevailing in the territory of climatic zone $\mathrm{D}$, affecting mains water temperature also. Furthermore, for both climatic zones, the demand towards the summer months is considerably lower than the one towards the winter ones, because of the differences in the temperature of mains water.

Afterwards, depending on the efficiency of each energy system, the energy consumption could be calculated in an hourly basis, according to Equation (3) [20]. Based on these values and the costs presented in Table 1, both energy and environmental costs are calculated.

$$
Q_{\text {cons }}=\frac{Q_{\text {dem }}}{n \text { or } C O P}
$$

where:

- Qdem [kWh]: required energy load (demand).

- $\mathrm{n}$ or COP [-]: efficiency of each energy system.

- $Q_{\text {cons }}[k W h]$ : consumed energy.

As far as the calculation of the installed power of each energy system is concerned, this could be done by using the daily energy demands and considering that the covering of these demands could be achieved in a five-hour operation, as defined in the respective technical guide for the Greek version of EPBD [20]. Especially regarding the case of the solar system, the dimensioning refers to the calculation of the respective collector surface. This calculation is made according to Equation (4), where the solar CF and the monthly available solar radiation are necessary. 


$$
A_{\text {sol }}=\frac{E_{\text {solHW }}}{C F_{\text {sol }} \cdot H_{\text {sol }}}=\frac{\frac{Q_{\text {demsol }}}{n_{\text {sol }}}}{C F_{\text {sol }} \cdot H_{\text {sol }}}
$$

where:

- $E_{\text {solHw }}$ [kWh]: useful energy, provided by the solar collector on monthly basis.

- $\mathrm{CF}_{\text {sol }}[-]$ : capacity factor for the solar energy, i.e., the efficiency of the solar collecting surface, calculated on a monthly basis $(=0.4)$ [20].

- $\mathrm{n}_{\text {sol }}[-]$ : efficiency of heat transfer $(=0.95)$.

- $\mathrm{A}_{\mathrm{sol}}\left[\mathrm{m}^{2}\right]$ : solar thermal collector area.

- $\mathrm{H}_{\mathrm{sol}}\left[\mathrm{kWh} / \mathrm{m}^{2}\right]$ : monthly available solar radiation on collectors' surface [21].

\subsection{Formulation of the baseline optimization model}

The target of the developed model is to select which system is appropriate to be used and to what participation rate in order to minimize the total cost. This could be achieved by the identification of the energy costs for each energy system, considering the hourly energy consumption, and the input of the participation rate for each energy system. In addition to that, the hourly installation costs for each energy system are added in the model concluding their life duration. This category of costs is a constant value for each energy system, which is taken into account only in cases where the operation of an energy system is beneficial for the model to minimize the total cost. For this reason, Equation (5), which is the objective function of the proposed problem, includes binary variables that are connected to the installation costs. Moreover, as far as the solar thermal system is concerned, its optimal participation is determined by the installation cost, because of its zero operational cost due to the abundant energy source this system uses.

$$
\begin{aligned}
& E_{\text {encost }}=\frac{Q_{d e m}}{} \cdot \text { encost }_{b l} \cdot e_{b l}+\frac{Q_{d e m} \cdot \text { encost }_{w d}}{n_{w d}} \cdot e_{w d}+\frac{Q_{d e m} \cdot \text { encost }_{e l}}{n_{e l}} \\
& \cdot e_{e l}+\frac{Q_{d e m} \cdot \text { encost }_{h p}}{n_{h p}} \cdot e_{h p}+\frac{A_{s o l} \cdot \text { inct }_{\text {sol }}}{y_{\text {sol }}} \\
& \cdot e_{\text {sol }}+\frac{P_{b l} \cdot \text { inct }_{b l}}{y_{b l}} \cdot a+\frac{P_{w d} \cdot \text { inct }_{w d}}{y_{w d}} \cdot b+\frac{P_{e l} \cdot \text { inct }_{e l}}{y_{e l}} \cdot c \\
&+\frac{P_{H P} \cdot \text { inct }_{h p}}{y_{h p}} \cdot d
\end{aligned}
$$

As mentioned above, Equation (5) is the objective function of the mathematical model and includes decision variables, that are used for its optimization, focusing on (or aiming to) minimizing the costs. These variables are the following:

- $e_{b l}, e_{w d}, e_{e l}, e_{h p}, e_{s o l}$ : the percentage decision variables that express the participation rate of each energy system. 
- $\quad a, b, c, d$ : the binary decision variables of each energy system that define the installation costs.

Of course, it is necessary to formulate constraints for the above variables. Their formula and interpretation are described below.

i. Non-negativity constraints of the participation rates.

$$
0 \leq e_{b l} \leq 1,0 \leq e_{w d} \leq 1,0 \leq e_{e l} \leq 1,0 \leq e_{h p} \leq 1,0 \leq e_{s o l} \leq 1
$$

ii. Constraint for full covering the demands.

$$
e_{b l} \leq a, e_{w d} \leq b, e_{e l} \leq c, e_{h p} \leq d
$$

iii. Constraints for the participation of the installation costs.

$$
e_{b l}+e_{w d}+e_{e l}+e_{h p}+e_{s o l}=1
$$

\subsection{Specific scenarios of optimization modelling}

\subsubsection{Energy model minimizing cost}

The basic scenario of the present model refers to the complete case, as described through Equations (5) - (8) in Section 2.2, implemented for both climatic zones, $A$ and $D$. Following, the energy hub excluding the biomass boiler has also been investigated, as the biomass solution is not so widely used for DHW in Greece.

\subsubsection{Environmental model minimizing cost}

The environmental optimization model is formulated as an energy balance equation, excluding the installation cost, while including the environmental one; thus, the binary variables are deleted. The investigated scenarios are the same with the ones of the energy optimization model. Equation (9) describes the objective function of the environmental model.

$$
\begin{gathered}
E_{\text {envcost }}=\frac{Q_{d e m} \cdot \text { envcost }_{b l}}{n_{b l}} \cdot e_{b l}+\frac{Q_{d e m} \cdot \text { envcost }_{w d}}{n_{w d}} \cdot e_{w d} \\
+\frac{Q_{d e m} \cdot \text { envcost }_{e l}}{n_{e l}} \cdot e_{e l}+\frac{Q_{d e m} \cdot \text { envcost }_{h p}}{n_{h p}} \cdot e_{h p} \\
+\frac{A_{\text {sol }} \cdot \text { inct }_{\text {sol }}}{y_{\text {sol }}} \cdot e_{\text {sol }}
\end{gathered}
$$

\subsubsection{Multi criteria model}

This model type concerns an integer linear programming model with an objective function that combines the objective functions of the previous energy and environmental models. In fact, the energy and environmental criteria are included into an optimization model, which 
aims to minimize both the energy and the environmental costs. The investigation of the multi criteria models concerns three model types, excluding the biomass boiler, while it is only applied into the climatic zone $D$. The first model type considers equal contribution of the two criteria in its objective function, as displayed in Equation (10). The other two model types insert weights in the criteria; on the one hand there is a weight $70 \%$ to the energy cost ( $\left.E_{\text {encost }}\right)$ and $30 \%$ to the environmental cost ( $\left.E_{\text {envcost }}\right)$, as it can be seen in Equation (11), and on the other hand, $30 \%$ weight to the energy and $70 \%$ to the environmental cost is anticipated (Equation (12)). The assumed weights have been selected in order to investigate potential differences in the results.

$$
\begin{gathered}
E_{\text {costs }}=E_{\text {encost }}+E_{\text {envcost }} \\
E_{\text {costs }}=0.7 \cdot E_{\text {encost }}+0.3 \cdot E_{\text {envcost }} \\
E_{\text {costs }}=0.3 \cdot E_{\text {encost }}+0.7 \cdot E_{\text {envcost }}
\end{gathered}
$$

\subsubsection{Goal programming model}

The Goal Programming (GP) model combines the energy and the environmental criteria, as they were formulated in Sections 3.2.1 and 3.2.2. The investigation introduces two GP models, the classical one which objective function is the sum of the deviation variables (Equation (13)), and the weighted one, where the energy criterion has twice the importance of the environmental criterion (Equation (14)). The two GP models include all the constraints of the baseline model, as described in Section 2.2, and other two that introduce the deviation variables, which actually comprise the objective function (Equation (15) and (16)). Of course, the non-negativity constraint for the deviation variables is crucial for the GP model, as described in Equation (17).

$$
\begin{gathered}
\min z=n_{1}^{-}+p_{1}^{+}+n_{2}^{-}+p_{2}^{+} \\
\min z=\frac{2}{E_{\text {encost }}} \cdot n_{1}^{-}+\frac{2}{E_{\text {encost }}} \cdot p_{1}^{+}+\frac{1}{E_{\text {envcost }}} \cdot n_{2}^{-}+\frac{1}{E_{\text {envcost }}} \cdot p_{2}^{+} \\
\text {s.t. } x_{1} \cdot e_{b l}+x_{2} \cdot e_{e l}+x_{3} \cdot e_{h p}+x_{4} \cdot e_{\text {sol }}+k_{1} \cdot a+k_{2} \cdot b+k_{3} \cdot c \\
+n_{1}^{-}-p_{1}^{+}=E_{\text {encost }} \\
y_{1} \cdot e_{b l}+y_{2} \cdot e_{e l}+y_{3} \cdot e_{h p}+y_{4} \cdot e_{\text {sol }}+n_{2}^{-}-p_{2}^{+}=E_{\text {envcost }} \\
n_{1}^{-}, p_{1}^{+}, n_{2}^{-}, p_{2}^{+} \geq 0
\end{gathered}
$$




\section{Results}

\subsection{Results of the energy model}

Figure 3 displays a histogram for the annual optimal energy cost consumed by each energy system of the energy hub, fully covering the DHW demands. These costs were depicted from the hourly solution of the energy optimization model for both climatic zones. So, it can be seen that a building located in climatic zone D consumes more energy, when compared to the case of climatic zone A. This can be explained because of the unfavorable climatic conditions prevailed in climatic zone D, leading to the selection of different participation rate from each energy system. Moreover, Figure 3 shows that the most preferred energy system for both climatic zones is the biomass boiler, due to its low energy cost, and followed by the heat pump for climatic zone D and the solar thermal system for climatic zone A. It is important to mention that the use of systems that collect solar energy, which is considered as a RES system, is favored for both climatic zones, presenting higher participation rate for climatic zone A due to the higher solar energy potential.

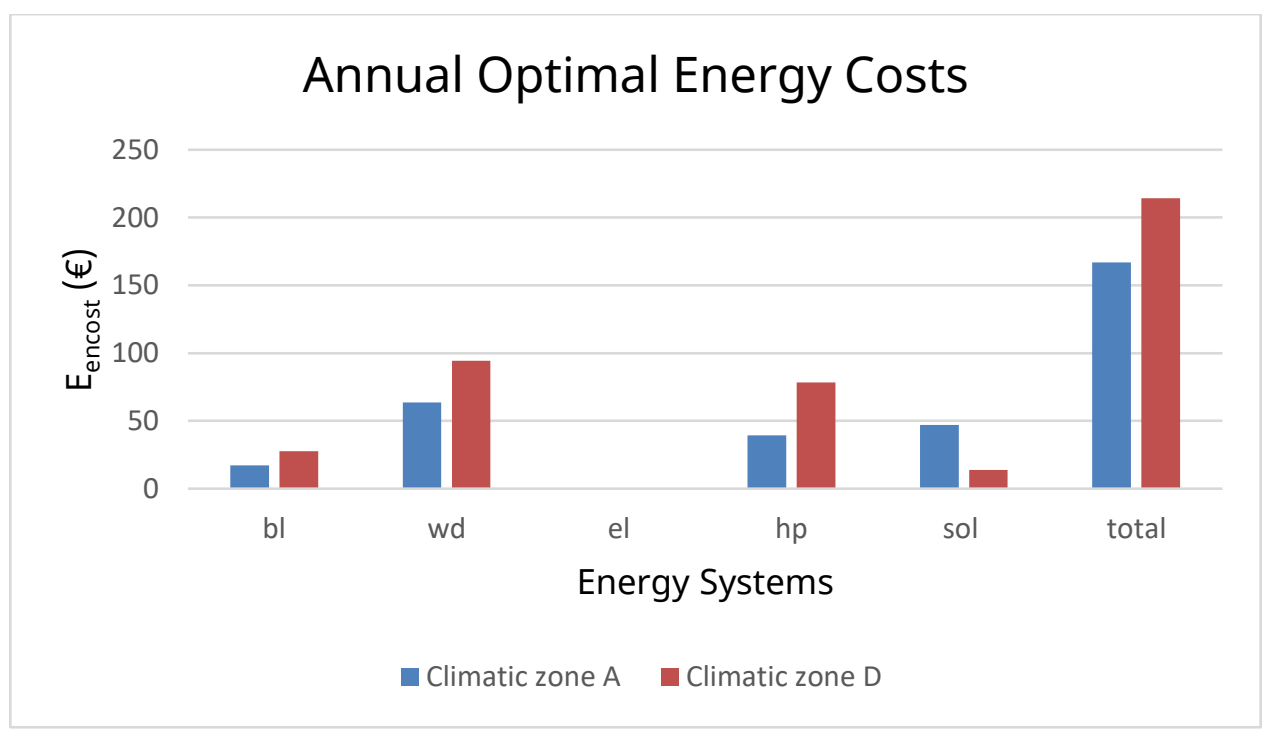

Figure 3 Total annual cost for each energy system, for climatic zones A and D.

In Figure 4, the operational time fraction, on annual basis, of each energy system is presented. It could be stated that the heat pump is dominant for both the climatic zones, followed by biomass in climatic zone $D$ and solar thermal system in climatic zone $A$. The operational time of the heat pump remains the same, presenting the greatest fraction, for both climatic zones, in comparison with the other energy systems due to the low energy cost; the assumption of the social-night tariff is applied. Despite the fact that these low energy cost values are the same for the electric energy system, its energy consumption and, consequently, its operational costs are higher than those of the heat pump. 
The above can be verified and further analyzed through the monthly fraction of the operational time. As it can be seen through Figure 5 and Figure 6, for both climatic zones, the biomass boiler is dominant during the winter months, but solar thermal collectors have higher participation during summer months; heat pump operation is almost constant for every month.

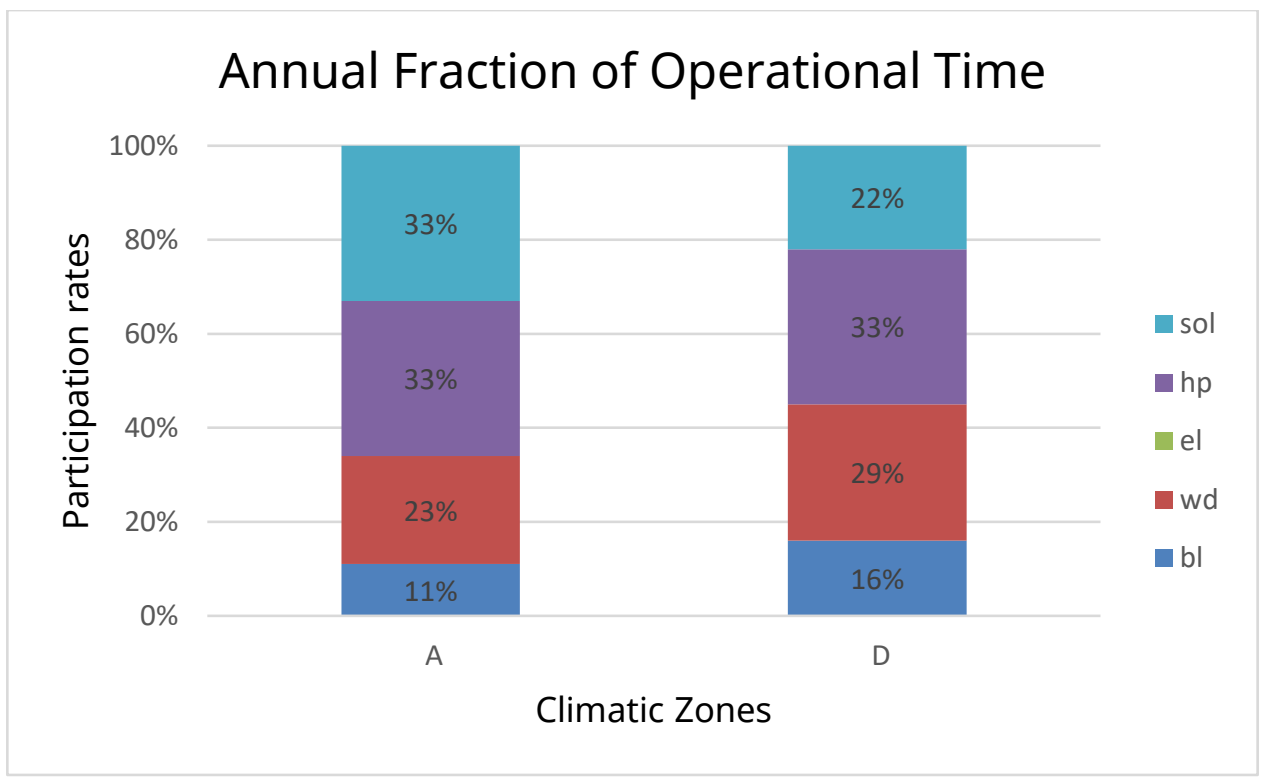

Figure 4 Fraction of the operational time, on annual basis, for each energy system and for both climatic zones.

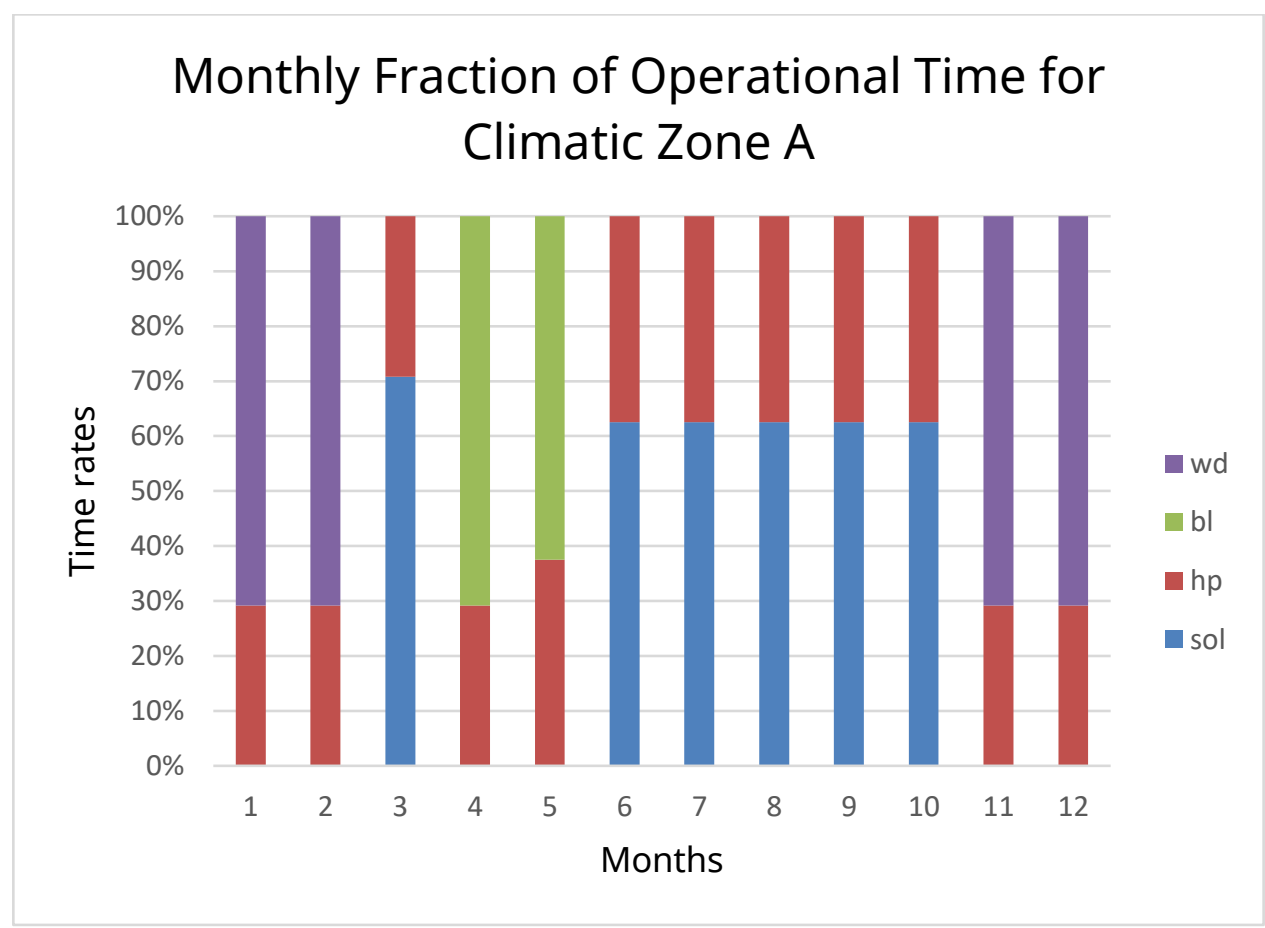

Figure $\mathbf{5}$ The monthly fraction of the operational time for climatic zone $\mathrm{A}$. 


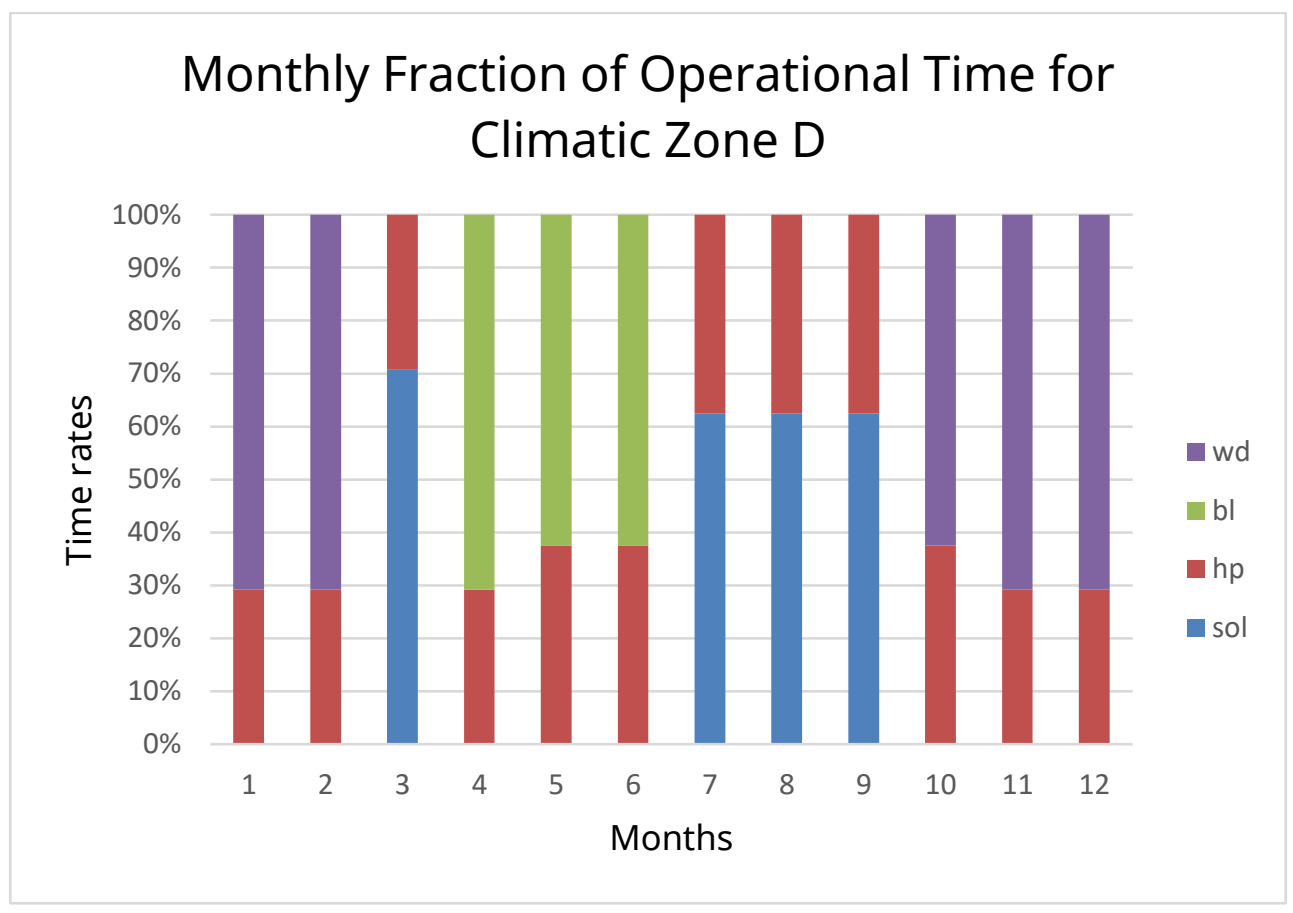

Figure 6 The monthly fraction of the operational time for climatic zone $\mathrm{D}$.

The additional examined energy model is that of excluding the biomass energy system. Results show that there is an increase in total minimized costs by $12 \%$ annually, due to the low cost of biomass. This occurs because the participation rate of biomass is primarily shared by the heat pump and the solar thermal collector.

\subsection{Results of the environmental model}

The results of this optimization model show that the RES ( $w d$ and sol) is the optional solution for minimizing the environmental cost for the two climatic zones. Considering the model that excludes biomass, solar thermal collectors dominate $100 \%$.

\subsection{Results of the multi criteria model}

The multi criteria model has been applied for climatic zone D, while not including the biomass boiler presence in the energy hub. The following results are obtained in Table 2, for the three types of models developed. According to these results, the participation of the oil and electrical boiler is not beneficial, so the cost minimization is succeeded only by the participation of the heat pump and the solar thermal collector. Regarding the weightless model, it should be mentioned that the total optimized cost is $40 \%$ less than the cost of the basic energy model due to the environmental consequences of the conventional energy systems, such as the electrical boiler. 
Table 2 Annual minimized cost for the multi energy models.

\begin{tabular}{c|c|c|c|c|c}
\hline & \multicolumn{5}{|c}{ Minimized cost (€) } \\
\hline Model type & bl & el & hp & sol & total \\
\hline Non weighted & 0 & 0 & 111.6 & 219.7 & 330.7 \\
70\%-30\% & 0 & 0 & 110.8 & 86.5 & 197.3 \\
$30 \%-70 \%$ & 0 & 0 & 13.8 & 103.5 & 117.3 \\
\hline
\end{tabular}

The diagram in Figure 7 presents the fraction of the operational time for each energy system for multi criteria models. The results of the weighted models presented both in Table 2 and Figure 7 show that when the more importance is given to the energy criterion, the total cost increases, and the participation of RES systems decreases.

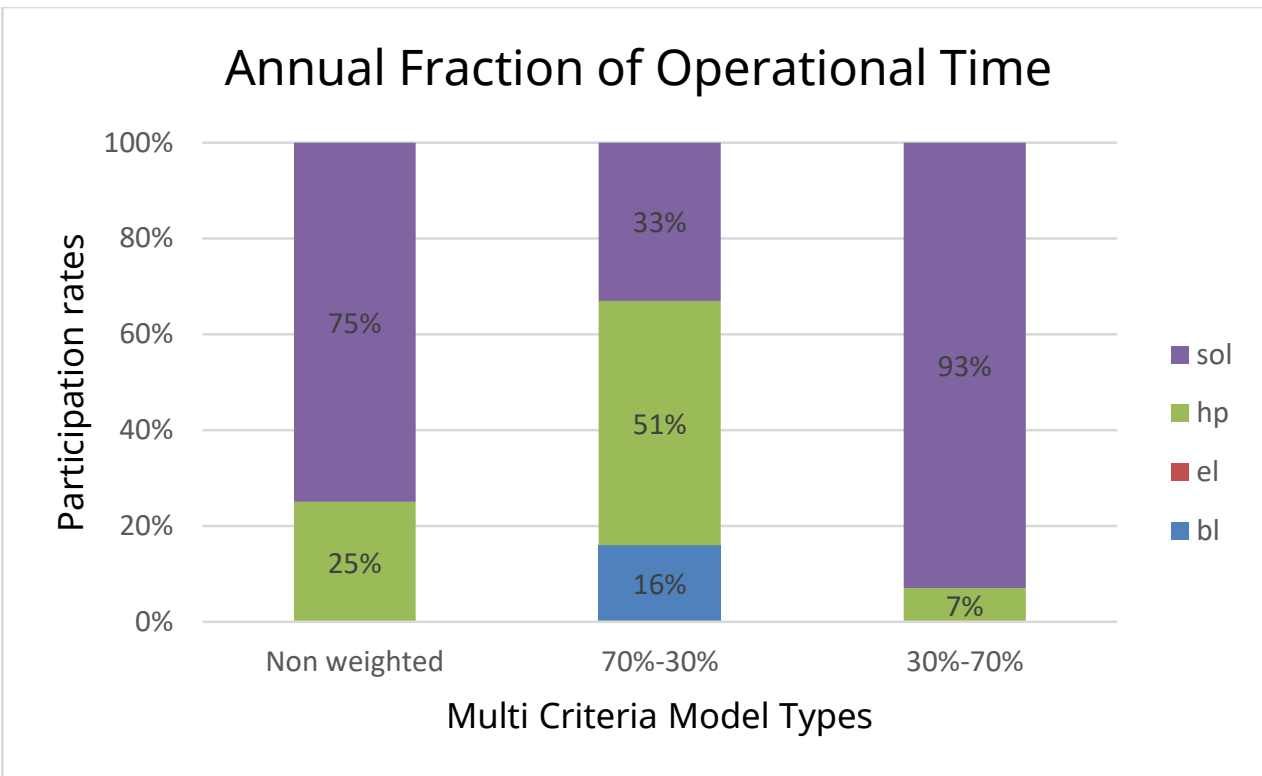

Figure 7 The annual distribution of the operational time for each energy system for the multi criteria models.

\subsection{Results of the goal programming model}

Figure 8 presents a histogram of the total annual optimized cost resulting from the solution in an hourly basis of the GP models. Two model types are examined, the classic GP model that includes the energy and the environmental criterion equally (without weights) and the weighted GP model, considering that the energy criterion is twice as important as the environmental one. Figure 8 displays the optimal costs distributed to the two examined criteria and the total costs for both GP models. As in the case of multi criteria, the GP model investigation has not included biomass energy system, due to it being applied into climatic zone D only. According to the results, it can be seen that for the classic GP model the total cost is increased in comparison with the basic energy and environmental models. The reason for this can be attributed to the relaxation regarding the success of the targets for each criterion. 


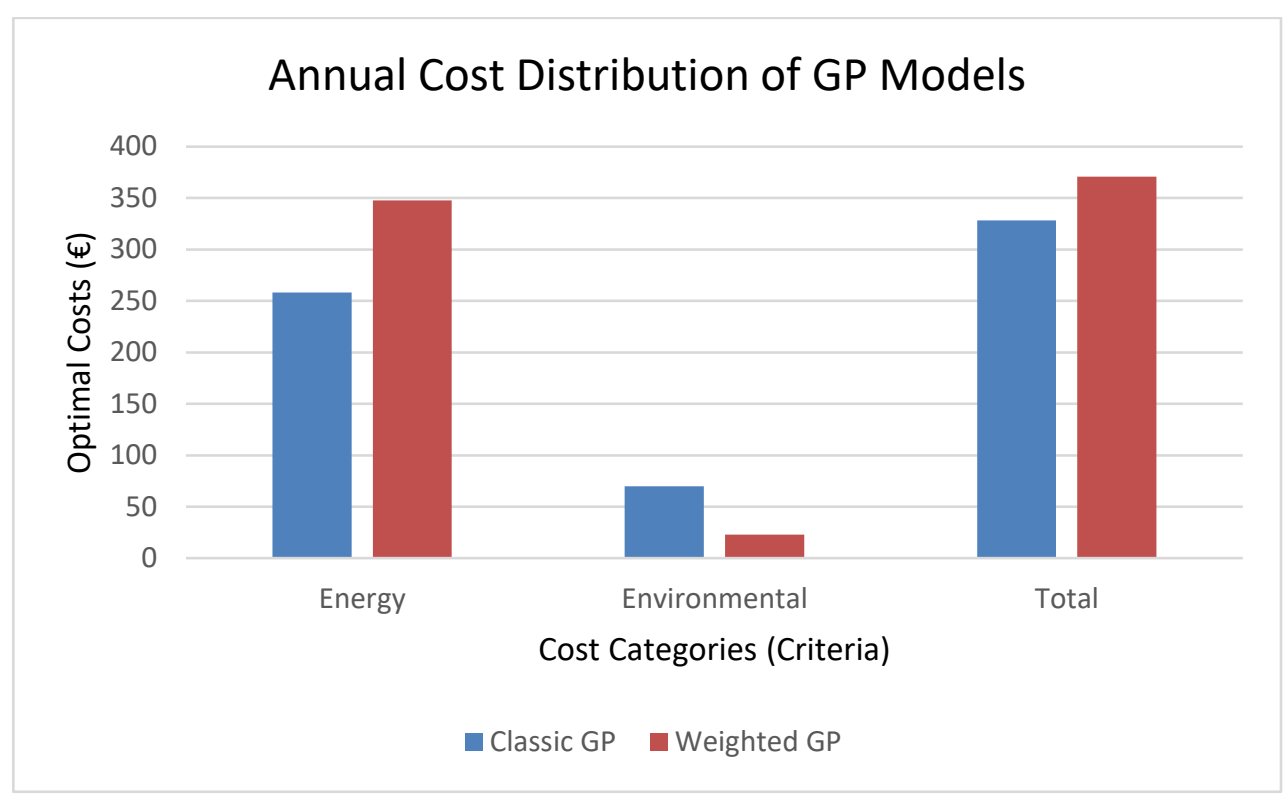

Figure 8 Annual minimized cost distribution for the GP models.

In addition to the above, it is crucial to present the rates of operational time distribution for each energy system used. Figure 9 shows this time distribution on an annual basis for the classic GP model and the energy model excluding the biomass boiler. Thus, for the classic GP model, it is observed that the only energy systems participating are the heat pump and the solar thermal system, with the last considered as more beneficial. This emerges a contrast to the results of the energy model because of the increased participation rate of RES systems in the GP model.

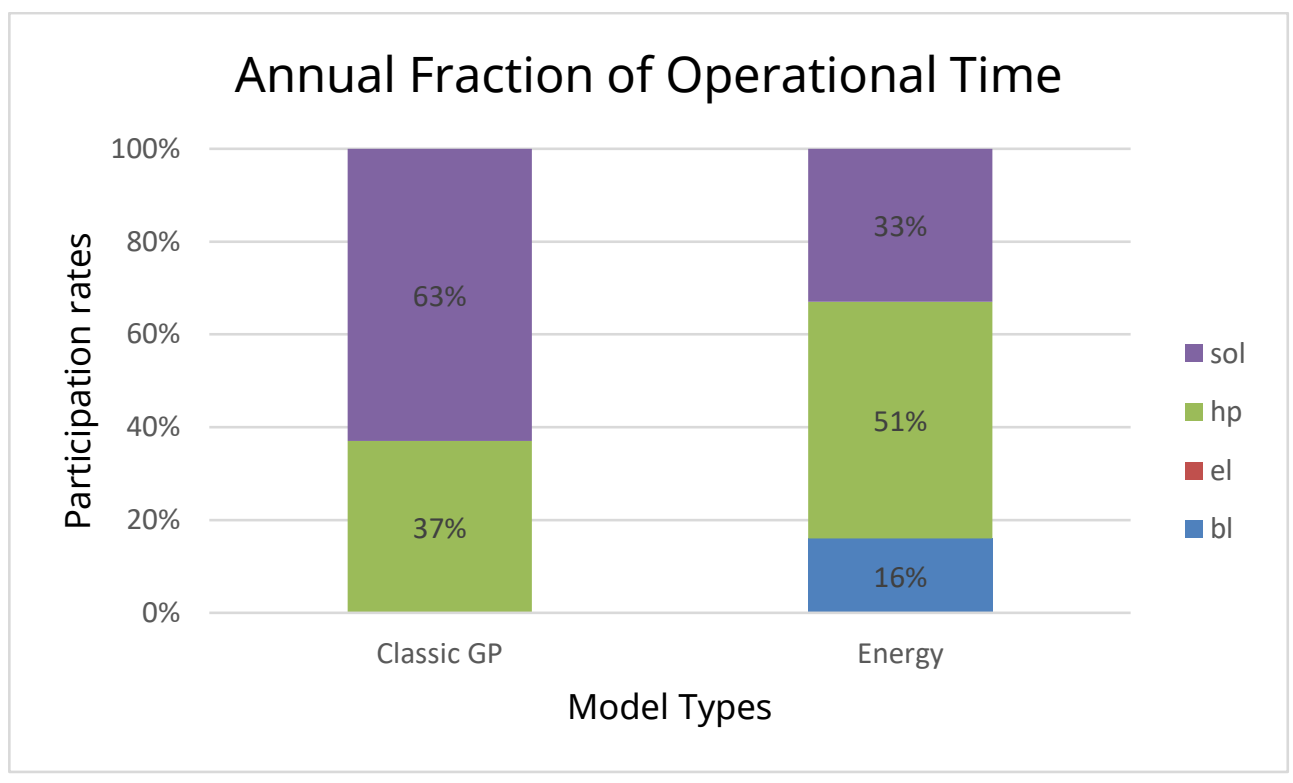

Figure 9 The annual fraction of the operational time for each energy system for the classic GP and the energy (excluding wd, only for climatic zone D) models. 
As for the weighted GP model, the results are approximately similar to the classic ones, and in comparison, with the multi criteria $70 \%-30 \%$ model, it could be seen that the participation of the most financial and environmental efficient technologies are beneficial (sol and hp).

\section{Conclusions}

The application of optimization algorithms in the design of multi energy systems provides, on one hand, the possibility of in-depth analysis of the parameters of the energy and environmental problem, and, on the other hand, the possibility of evaluating the results towards the limitation of conventional energy sources, according to the suggestions of the calculated rates of participation. The elaboration of a methodology for decision making on energy systems, in combination with the use of a rather small-time step, in terms of energy design, that of one hour, provides a dynamic character to the problem.

According to the present case study for the domestic water heating in a household, in terms of the energy criterion, the optimal energy system is the biomass boiler (or the heat pump for models excluding the biomass), while on an environmental level, the solar thermal system increases its participation. Furthermore, when the GP models involve both energy and environmental criteria, due to potential relaxation from the primary goals, the participation of RES, i.e., solar thermal system, increases.

Further research may focus on utilizing a larger range of mathematical programming models and methods, as well as on problem solving with a shorter time step. The time step decrease may change the design problem to a controlling problem. Moreover, a Life Cycle Assessment (LCA) analysis would enrich the environmental model, allowing a more complete and accurate evaluation of the environmental impact of each energy system. The investigation could also be extended to different types of energy systems, as well as of buildings, including all climatic zones; the uses can also be extended, referring to space heating and cooling.

\section{Ethics Statement}

Not applicable.

\section{Consent for Publication}

Not applicable.

\section{Availability of Data and Material}

Not applicable. 


\section{Funding}

This research was not funded.

\section{Competing Interests}

The authors have declared that no competing interests exist.

\section{Author Contributions}

VK conducted the simulation analysis and was in charge of writing the article. NP supervised the Mathematical Programming section and reviewed the manuscript. GP directed the research and reviewed the manuscript.

\section{Abbreviations}

The following abbreviations are used in this manuscript:

DHW Domestic Hot Water

EPBD European Performance of Buildings Directive

EU European Union

GAMS General Algebraic Modeling System

GP Goal Programming

LCA Life Cycle Assessment

nZEB near Zero Energy Building

RES Renewable Energy Sources

bl oil boiler

el electric water heater

hp heat pump

sol solar thermal heater

wd biomass boiler

\section{References}

1. Eurostat, 2021. Statistics explained - Energy statistics - an overview. 2019. Available at: https://ec.europa.eu/eurostat/statisticsexplained/index.php?title=Energy_statistics_-

_an_overview\#Primary_energy_production (Access on 27 September 2021).

2. EU, 2002. Directive 2002/91/EP of the European Parliament and of the Council of $16^{\text {th }}$ December 2002 on the energy performance of buildings. Brussels.

3. EU, 2018. Directive 2018/844/EP of the European Parliament and of the Council of 30 th May 2018 amending Directive 2010/31/EU on the energy performance of buildings and Directive 2012/27/EU on energy efficiency. Brussels. 
4. European Commission. 2014. Communication from the Commission to the European Parliament, the Council, the European Economic and Social Committee and the Committee of the regions. A policy framework for climate and energy in the period from 2020 to 2030. Brussels.

5. Pezzutto S, Croce S, Zambotti S, Kranzl L, Novelli A, Zambelli P. Assessment of the Space Heating and Domestic Hot Water Market in Europe - Open Data and Results. Energies. 2019;12:1760. DOI

6. Fuentes $E$, Arce L, Salom J. A review of domestic hot water consumption profiles for application in systems and buildings energy performance analysis. Renew Sust Energ Rev. 2018;81:15301547. DOI

7. Tumanova K, Borodinecs A, Geikins A. The analysis of the hot water consumption and energy performance before and after renovation in multi-apartment buildings. IOP CONF SER-MAT SCI. 2017;251:012058. DOI

8. Eurostat, 2021. Energy Balance Sheets 2019. Available at: https://ec.europa.eu/eurostat/statistics-

explained/index.php?title=Energy_consumption_in_households\#E nergy_consumption_in_households_by_type_of_end-use (Access on 27 September 2021).

9. Manwell JF, Cleveland CJ. Hybrid energy systems - Encyclopedia of energy. $1^{\text {st }}$ ed. London, UK: Elsevier: 2004; P. 215-229.

10. Ooka R, Komamura K. Optimal design method for building energy systems using genetic algorithms. Build. Environ. 2009;44:1538-1544. DOI

11. Fabrizio E, Corrado V, Filippi M. A model to design and optimize multi-energy systems in buildings at the design concept stage. Renew Energ. 2010;35:644-655. DOI

12. Pierluigi M. MES (multi-energy systems): An overview of concepts and evaluation models. Energy. 2014;65:1-17. DOI

13. Bayod-Rújula AA, Yuan Y, Martínez-Gracia A, Wang J, Uche J, Chen H. Modelling and simulation of a building energy hub. Proceedings 2018;2:1431. DOI

14. Shuangjun $X$, Chengchu $Y$, Chen J. Design optimization of hybrid renewable energy systems for sustainable building development based on energy-hub. Energy Procedia 2019;158:1015-1020. DOI

15. Ha T, Zhang Y, Thang VV, Huang J. Energy hub modeling to minimize residential energy costs considering solar energy and BESS. J Mod Power Syst Clean Energy. 2017;5:389-399. DOI

16. Martinopoulos G, Papakostas K, Papadopoulos A. Comparative analysis of various heating systems for residential buildings in Mediterranean climate. Energy Build. 2016;124:79-87. DOI

17. Martinopoulos G, Papakostas K, Papadopoulos A. A comparative review of heating systems in EU countries, based on efficiency and fuel cost. Renew Sustain Energy Rev. 2018;90:687-699. DOI 
18. Panagiotidou M, Aye L, Rismanchi B. Optimisation of multi-residential building retrofit, cost-optimal and net-zero emission targets. Energy Build. 2021;252:111385. DOI

19. Gaglia A, Dialynas E, Argiriou A, Kostopoulou E, Tsiamitros D, Stimoniaris D, Laskos K. Energy performance of European residential buildings: Energy use, technical and environmental characteristics of the Greek residential sector - energy conservation and $\mathrm{CO}_{2}$ reduction. Energy Build. 2019;183:86-104. DOI

20. TEE. Technical Directive of the Technical Chamber of Greece (TEE) 20701-1: Analytical technical specifications of parameters for the calculation of buildings' energy performance and the issuing of energy performance certificate; TEE: Athens, Greece, 2017.

21. TEE. Technical Directive of the Technical Chamber of Greece (TEE) 20701-3: Climatic Data for Greek Areas; TEE: Athens, Greece, 2017.

22. Mouzeviris G, Papakostas K. Comparative analysis of air-to-water and ground source heat pumps performances. Int J Sustain 2021;40:69-84. DOI

Cite this article: Kilis V, Ploskas N, Panaras G. Design optimization of multi energy systems for domestic hot water uses on the building sector. Green Energy Sustain. 2021;1(2),0006.

https://doi.org/10.47248/HKOD902101020006. 